\title{
Use of dermal regeneration template to close a giant myelomeningocele in a newborn
}

\author{
William D. North, MD, ${ }^{1}$ Laith Khoury, MD, ${ }^{2}$ R. Christopher Spears, MD, ${ }^{2}$ James Y. Liau, MD, ${ }^{1}$ and \\ Thomas Pittman, MD² \\ 'Division of Plastic and Reconstructive Surgery; and 'Department of Neurosurgery, University of Kentucky College of Medicine, \\ Lexington, Kentucky
}

\begin{abstract}
Many techniques are available to close a myelomeningocele, but large lesions can be particularly difficult to close given the absence of surrounding tissue. The authors present the case of a 2-day-old girl with a large lumbosacral myelomeningocele who underwent a staged repair using dermal regeneration template (DRT; Integra) followed by split-thickness skin grafting. The results demonstrated that the combined use of myofascial turnover flaps and DRT with delayed skin grafting is a safe, effective option for this challenging reconstructive dilemma.
\end{abstract}

http://thejns.org/doi/abs/10.3171/2016.6.PEDS16127

KEY WORDS myelomeningocele repair; dermal regenerative template; spina bifida cystica; congenital

$\mathrm{M}$ YELOMENINGOCELE is the most common type of spina bifida, presenting in nearly 1 of 800 babies born in the US. ${ }^{7}$ Though the incidence of myelomeningoceles has decreased significantly since 1988, their repair remains a relatively common procedure. ${ }^{4}$

Many closure techniques have been presented, including simple primary closure and the use of myofascial flaps and skin grafts, though there is no single technique that is universally applicable. Studies have shown that there may be no difference in complication rates among the use of fasciocutaneous flaps, myocutaneous flaps, or primary closure. ${ }^{3}$ However, large defects can present a particular problem because of the lack of soft tissue available for coverage, making some techniques unfeasible or impossible. In these situations, other materials can be useful in closing the defects. Integra's dermal regeneration template (DRT) has been used to repair skin defects when there is insufficient native tissue for the repair. It is a bilayer membrane system involving a dermal replacement layer, composed of bovine tendon collagen and glycosaminoglycan with a defined degradation rate, and a silicone layer, which serves as an epidermal substitute and controls moisture loss from the wound. The silicone layer is removed approximately 21 days after DRT application when a new dermal layer has formed, and an autograft is applied. The DRT has been shown to be an effective tool with very few complications, with dryness and pruritis being the most common complaints. ${ }^{6}$ Its use in the context of burns and other reconstructive dilemmas in older populations has been described in the literature for well over a decade, but there has been very little description of its use in newborns. ${ }^{6,8,9}$ Though there are reports of its use to repair myelomeningoceles in utero, there has been only one other report of its application in repairing a myelomeningocele postnatally. $1,2,5$ The present case demonstrates the application of a bilayer regenerative matrix wound dressing for a staged reconstruction in the repair and closure of a giant $\left(24 \mathrm{~cm}^{2}\right)$ myelomeningocele in a newborn. 


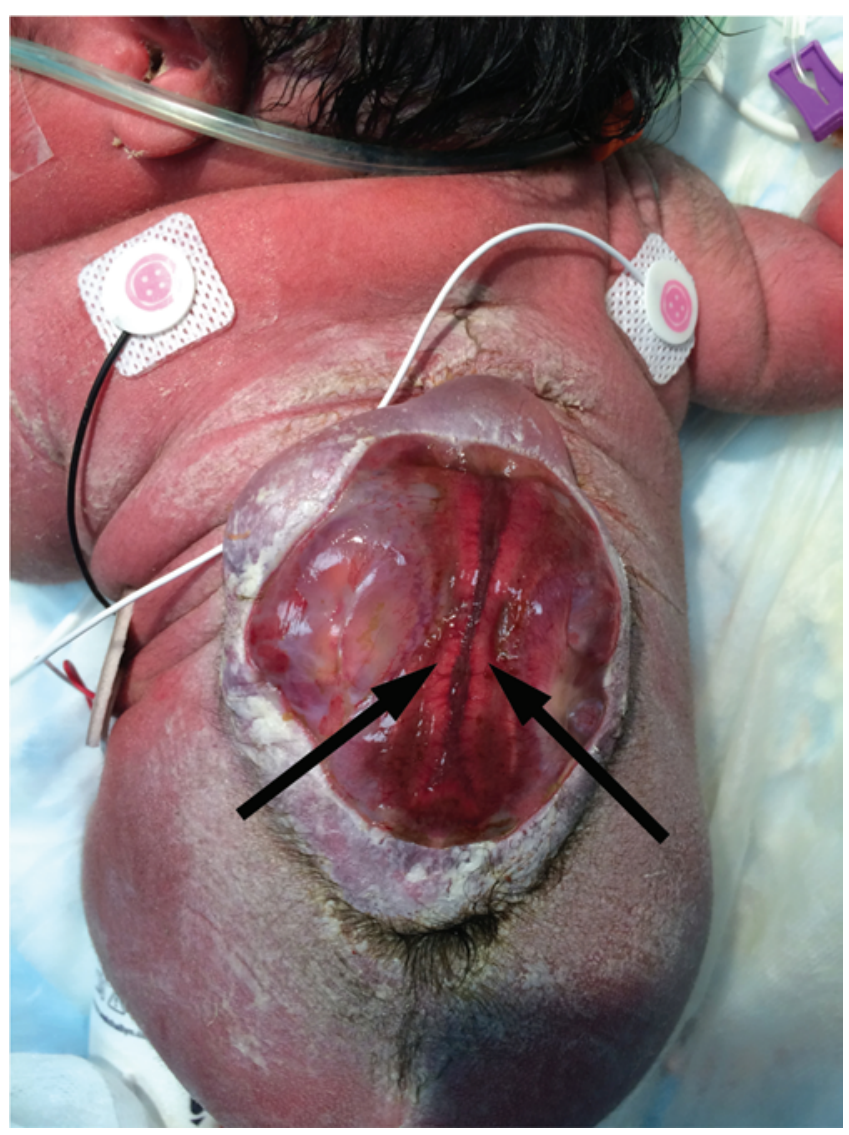

FIG. 1. Intraoperative photograph of the large myelomeningocele with visible dural edges (arrows). Figure is available in color online only.

\section{Case Report}

\section{History and Examination}

This 2-day-old female, weighing $3450 \mathrm{~g}$, was born at 38 weeks' gestation to a 35-year-old G4, P4 mother. The pregnancy was complicated by Type 1 diabetes. Fetal ultrasound demonstrated bilateral clubbed feet, ventriculomegaly, and a myelomeningocele. On examination, the child demonstrated no movement in the distal lower extremities bilaterally. A large lumbosacral myelomeningocele measuring $8.5 \times 6.5 \mathrm{~cm}$ (Fig. 1) was found. Magnetic resonance imaging did show hydrocephalus, but no shunt was placed before the initial myelomeningocele repair, and the patient's neurological examination was otherwise unremarkable.

\section{Operation}

She was taken to the operating room on her 2 nd day of life. The neurosurgical team repaired the neural defect; the cord was reintubulated using 5-0 chromic sutures, and the dura mater was elevated and closed with 6-0 running Prolene sutures (Fig. 2A).

Next, the plastic surgery team proceeded with the softtissue closure. Initially, skin flaps were raised around the placode, taking them all the way to the lateral aspect of the back bilaterally. The gluteus and latissimus muscles were identified, and an incision was made through the fascia into the muscle itself to allow for elevation. Dissection was then performed from lateral to medial, creating muscle
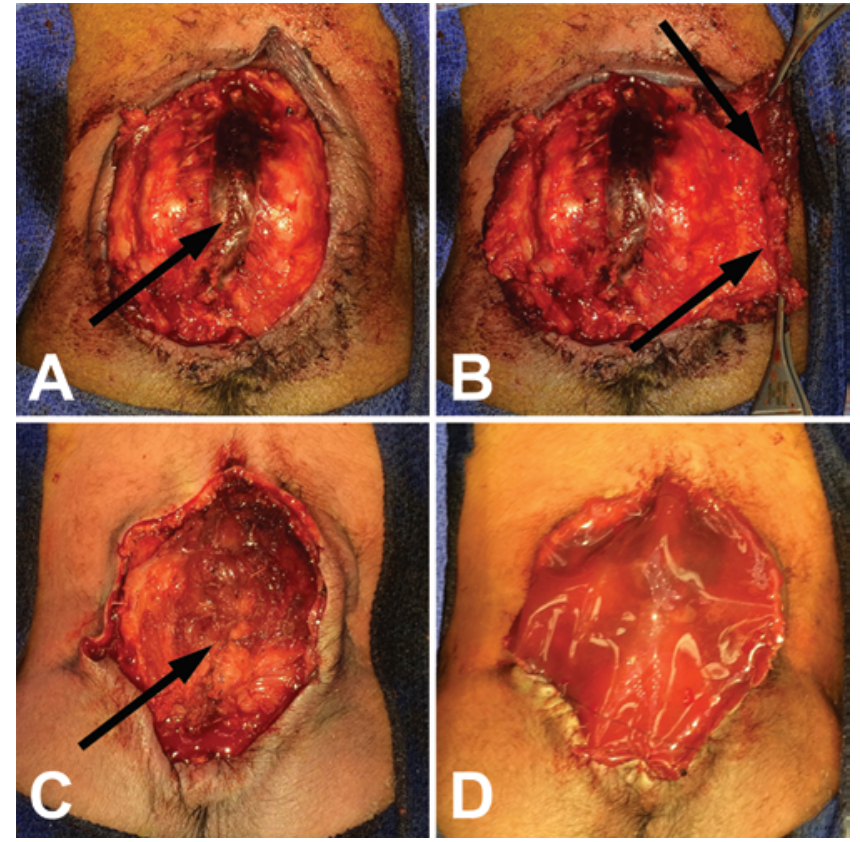

FIG. 2. Intraoperative photographs show closure of the dura (arrow, A), a turnover myofascial flap (arrows, B), closure of bilateral myofascial flaps (arrow) covering the repaired dural defect (C), and DRT placement over skin defect (D). Figure is available in color online only.

turnover flaps $7 \mathrm{~cm}$ long and $5 \mathrm{~cm}$ wide up to the placode to cover the exposed dural repair (Fig. 2B). The flaps were then turned over and reapproximated across the midline using Vicryl sutures in a figure- 8 fashion. The skin was sutured down to the placode itself to obliterate the dead space (Fig. 2C). A $6 \times 4-\mathrm{cm}$ sheet of DRT was used to cover the muscle flaps and was secured to the surrounding skin using 5-0 plain gut sutures (Fig. 2D).

\section{Postoperative Course}

Postoperatively, the patient had significant truncal and lower extremity hypotonia and a neurogenic bladder. Postoperative video electroencephalography revealed no seizures. Repeat imaging demonstrated progressively enlarging ventricles, and a right occipital ventriculoperitoneal shunt was placed 10 days after the repair.

Following a 3-week period to allow for regeneration of the dermis, the patient returned to the operating room for removal of the outer silicone layer (Fig. 3A) and placement of an 8/1000-in-thick split-thickness graft. The graft was harvested from the right posterior thigh and meshed at a ratio of 1:1.5 prior to placement on the wound. The graft was secured to our muscle flaps using human fibrin sealant spray (Fig. 3B). Final coverage over the wound included a silver Dermanet bolster dressing (DeRoyal Industries, Inc.), while the Mepilex Ag (Mölnlycke Health Care) was applied to the donor site (Fig. 3C).

The silver bolster dressing remained over the splitthickness skin graft for a period of 7 days. Upon removing the dressing, we found the skin graft to have near-complete take. Local wound care for 2 more weeks resulted in a well-healed defect without complications. The patient has continued to do well with a stable reconstruction upon follow-up 3 months after the initial repair (Fig. 4). 

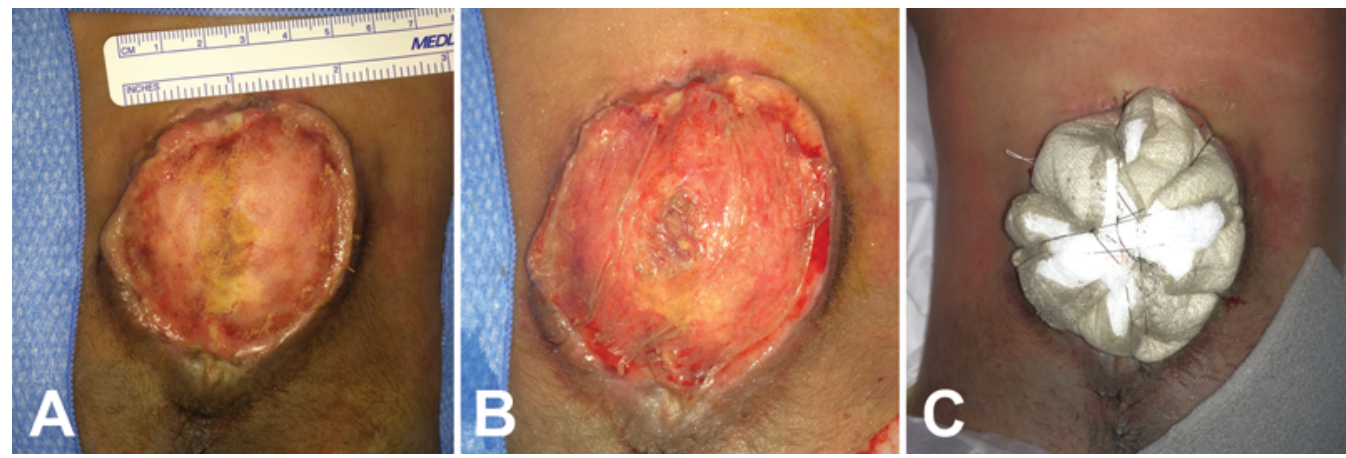

FIG. 3. Intraoperative photographs show removal of the silicone layer of the DRT (A), placement of a split-thickness skin graft to the DRT (B), and placement of a silver Dermanet bolster to prevent shearing of the skin graft (C). Figure is available in color online only.

\section{Discussion}

The goal of myelomeningocele repair is closure of the neural elements and stable closure of the soft tissue. Ideally, the repair is performed within the first 48 hours of the child's life since delaying closure increases the incidence of meningitis. Closing the cord and dura recreates a closed CSF compartment. However, this is just one component of the repair since a stable soft-tissue envelope is needed to prevent exposure of the newly repaired dura. Depending on the size of the soft-tissue defect, techniques for softtissue reconstruction extend along a spectrum ranging from primary closure to extensive skin and muscle flap reconstruction.

The closure of large defects often requires myocutaneous or cutaneous flaps, but such flaps require donor sites, which can be large and can cause morbidity for the patient. Larger skin flaps also increase the risk of necrosis and wound healing problems, which in turn jeopardizes the dural repair. A DRT over vascularized tissue provides another option in giant myelomeningocele repair; this option dramatically decreases donor site morbidity for the child while providing a stable, durable repair. Although there are reports of using DRT directly on dura, we feel that providing vascularized fascial muscle turnover flaps is preferable since it offers another layer of healthy tissue over the dura, as well as an optimal template for DRT vascularization.
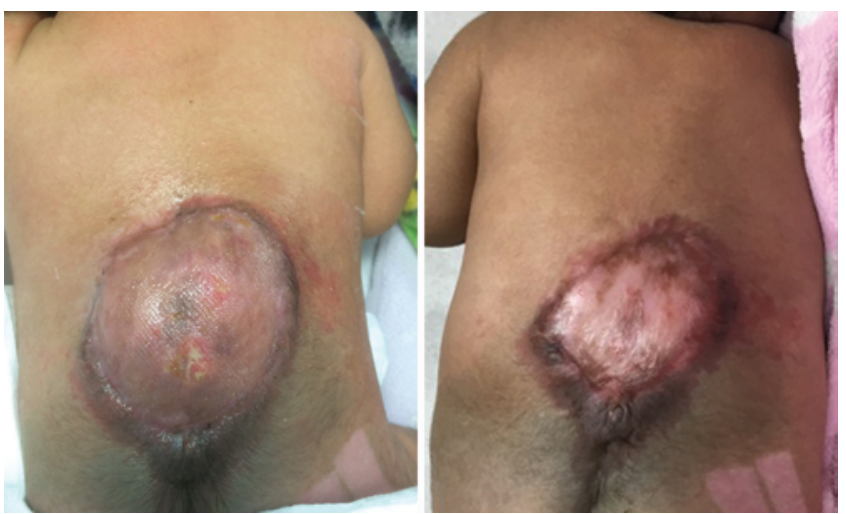

FIG. 4. Photographs show follow-up at 2 weeks after application of the split-thickness skin graft (left) and 3 months after initial repair (right). Figure is available in color online only.

\section{References}

1. Bevilacqua NS, Pedreira DA: Fetoscopy for meningomyelocele repair: past, present and future. Einstein (Sao Paulo) 13:283-289, 2015

2. Ghazi BH, Williams JK: Use of Integra in complex pediatric wounds. Ann Plast Surg 66:493-496, 2011

3. Kobraei EM, Ricci JA, Vasconez HC, Rinker BD: A comparison of techniques for myelomeningocele defect closure in the neonatal period. Childs Nerv Syst 30:1535-1541, 2014

4. Kshettry VR, Kelly ML, Rosenbaum BP, Seicean A, Hwang L, Weil RJ: Myelomeningocele: surgical trends and predictors of outcome in the United States, 1988-2010. J Neurosurg Pediatr 13:666-678, 2014

5. Meuli M, Meuli-Simmen C, Flake AW, Zimmermann R, Ochsenbein N, Scheer I, et al: Premiere use of Integra ${ }^{\mathrm{TM}}$ artificial skin to close an extensive fetal skin defect during open in utero repair of myelomeningocele. Pediatr Surg Int 29:1321-1326, 2013

6. Moiemen NS, Staiano JJ, Ojeh NO, Thway Y, Frame JD: Reconstructive surgery with a dermal regeneration template: clinical and histologic study. Plast Reconstr Surg 108:93103,2001

7. Persad VL, Van den Hof MC, Dubé JM, Zimmer P: Incidence of open neural tube defects in Nova Scotia after folic acid fortification. CMAJ 167:241-245, 2002

8. Ryan CM, Schoenfeld DA, Malloy M, Schulz JT III, Sheridan RL, Tompkins RG: Use of Integra artificial skin is associated with decreased length of stay for severely injured adult burn survivors. J Burn Care Rehabil 23:311-317, 2002

9. Verbelen J, Hoeksema H, Pirayesh A, Van Landuyt K, Monstrey S: Exposed tibial bone after burns: Flap reconstruction versus dermal substitute. Burns 42:e31-e37, 2016

\section{Disclosures}

The authors report no conflict of interest concerning the materials or methods used in this study or the findings specified in this paper.

\section{Author Contributions}

Conception and design: Pittman, North, Liau. Drafting the article: Pittman, North, Khoury, Spears. Critically revising the article: all authors. Reviewed submitted version of manuscript: all authors. Approved the final version of the manuscript on behalf of all authors: Pittman. Imaging formattting: Spears.

\section{Correspondence}

Thomas Pittman, Department of Neurosurgery, University of Kentucky College of Medicine, 800 Rose St., MS105, Lexington, KY 40536. email: tpitt2@uky.edu. 